\title{
Transcriptomics and micronutrient research
}

\author{
Ruan M. Elliott* \\ Institute of Food Research, Norwich Research Park, Colney, Norwich NR4 7UA, United Kingdom
}

This review examines the extent to which transcriptomic methods have lived up to their promise in the context of nutrition research, placing particular emphasis on examples from micronutrient research. A case is made that the high quality platform technologies now available, together with established standards and systems for data storage and exchange and powerful new methods of data analysis, mean that microarrays have reached a level of technical maturity at which they can be exploited to their full potential. In the context of nutrition and micronutrient research, transcriptomic methods have already been widely applied, albeit primarily in studies using cell lines and animal models. Using this type of approach, a multitude of genes regulated at the mRNA level by dietary components has been identified and this, in turn, has provided new insights into the biological processes affected by nutritional parameters. Evidence from the very limited number of published transcriptomics-based nutritional studies performed in human volunteers suggests that, with appropriate study design, it is feasible to apply transcriptomic methods successfully in dietary intervention trials. On the other hand, gene expression-based biomarker development still poses a major challenge. Here the use of expression profile 'signatures', rather than single genes, may provide a solution. Approaches designed to identify such 'signatures' are being developed and tested widely, primarily in the context of medical research. The applicability and power of such approaches should also be evaluated in the context of nutrition.

Nutritional genomics: Micronutrient: Transcriptomics: Microarray

Functional genomic approaches (e.g. transcriptomics, proteomics and metabolomics) have, for a number of years, been heralded as presenting enormous potential for advancement of nutritional research by providing new insights into dietgene interactions and for the development of new robust biomarkers of nutritional status ${ }^{(1-5)}$. The technologies available for functional genomic research continue to expand and be refined. This progress constantly improves the scope for nutrigenomic research. But to what extent have the 'omics' so far lived up to their hype in advancing our understanding of dietgene and nutrition-health interactions? This article will focus on technical progress with transcriptomic methods, their application to date for nutrition research, with particular emphasis upon micronutrients, and future needs and opportunities.

\section{Current status of transcriptomic technologies}

The first microarrays were developed over 10 years ago ${ }^{(6)}$ but the realisation of the full potential of transcriptomics has been held up to some extent by the inevitable need for adequate technology development. In the interim, there have been problems associated with data quality, data analysis methods, genome coverage and genome annotation. Now these issues appear to have been largely resolved. For example, concerns about the ability to obtain reproducible results across different array platform technologies no longer appear to be legitimate since the MicroArray Quality Control project demonstrated that is it possible to obtain high concordance in inter-site and cross-platform comparisons using well established commercial array platforms ${ }^{(7)}$. The range and scope of methods for analysing array data have also improved dramatically over the last few years so that it is now feasible to reliably identify even quite subtle alterations in the mRNA levels of discrete genes and to start to interpret alterations in gene expression profiles in the context of pathways, biological processes and cell signalling mechanisms. Examples of such approaches are discussed below.

Transcriptome coverage is no longer a genuine concern, since (i) the number of genes in mammalian genomes has proven to be far lower than initially expected and (ii) platform technologies have improved to a point at which the number of features that can be represented on a single array far exceeds the number of genes in a genome. Indeed, this has made it possible to extend the scope of microarrays to examine more than just mRNA levels for all genes. For example, array technologies exist that cover every individual gene exon, thus enabling expression analysis at the level of gene splice variants ${ }^{(8,9)}$. In fact, DNA arrays are also being applied to perform a wider range of analyses including genome-wide DNA methylation profiling, high-throughput genotyping and haplotying, comparative genomic hybridization for copy number determination and microRNA expression profiling (Fig. 1).

Another equally important issue has been the development and adoption of (i) standards for capturing microarray and associated study metadata (MIAME) ${ }^{(10)}$, standards and systems for exchanging microarray data (MAGE-OM and

Abbreviations: GEO, gene expression omnibus; MIAME, minimum information about microarray experiments; MAGE-OM, microarray gene expression-object model; MAGE-ML, microarray gene expression-markup language.

* Corresponding author: Dr Ruan Elliott, fax 01603 507723, email ruan.elliott@bbsrc.ac.uk 


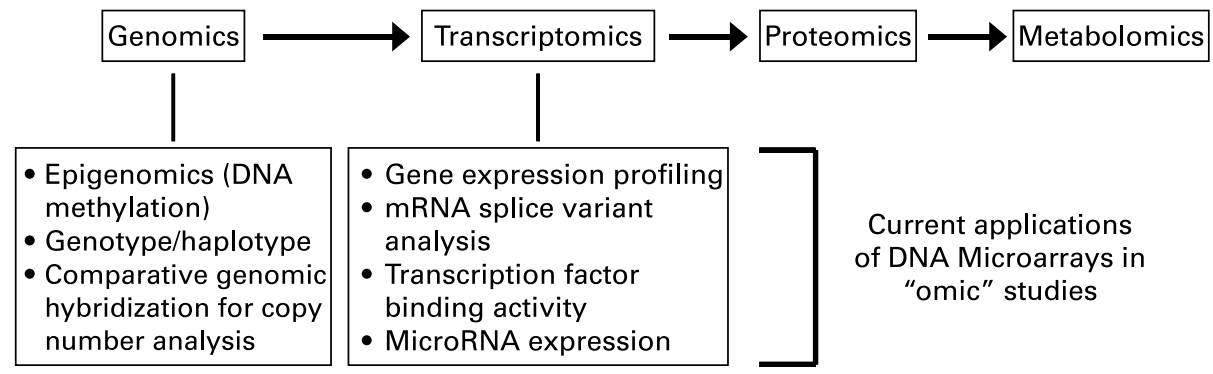

Fig. 1. Schematic representation of the current range of applications for DNA microarray-based technologies in the broader context of structural and functional 'omic' research areas.

MAGE-ML) ${ }^{(11)}$, (iii) open access resources, such as GEO and ArrayExpress $^{(12,13)}$, that make published microarray data freely available to all, and (iv) initiatives to provide research communities with common sets of descriptors (controlled vocabularies) arranged in ontologies (http://obi.sourceforge. net). Together, these efforts reflect the viewpoint that, given the significant level of resource that has to be put into microarray studies and the huge volume of data generated, this process should be considered a long-term investment for the benefit of the whole research community. These standards, systems and structures provide key elements of a framework to make the most of the stored data: facilitating the development of new analytical methods, helping in the training of new researchers and providing the scope for detailed structured searches of stored data and mining of data combined from multiple studies ${ }^{(14)}$.

Thus, overall, it seems reasonable to assert that transcriptomic technology has finally achieved a level of technical maturity that means it is feasible for committed researchers to generate high quality experimental data and, with appropriate statistical and bioinformatics expertise, to extract robust biological information from that data.

\section{Current application of transcriptomics in nutrition research}

In the context of nutrition research, transcriptomic methods have already been applied fairly extensively, most commonly using the general study design format depicted in Fig. 2.

Tables 1 and 2 illustrate the types and range of studies published in the context of micronutrient research, listing examples of microarray studies that have examined patterns of gene expression associated with varying iron and zinc exposure or status, respectively. Similar tables could equally be drawn up for many other nutrients, micronutrients and non-nutrient components of the diet.
Two key observations can be made from the information in these tables. The first is that all the transcriptomic studies listed have been performed in animal models, mammalian cell lines or primary human cells ex vivo, but not in samples derived from human nutritional intervention studies. The second is that, whist these studies have served to identify a host of genes that are regulated at the level of mRNA by different nutritional components, this information has not yet been combined to provide a single coherent overview and has not yet led to the development of new biomarkers. These two observations hold true in general across the spectrum of nutrition research and are discussed in more detail in the following sections.

\section{The scope for transcriptomics-based nutritional studies in human subjects}

Proponents of transcriptomic approaches should particularly note the general absence of microarray data obtained from human nutritional intervention studies. Presumably this reflects a general reticence to undertake such time-consuming and resource-intensive work without confidence that it will yield useable and valuable data: limitations in access to target tissues, technical challenges of isolating sufficient high quality RNA and the analytical problems of dealing with inter-individual variation in human subjects are all valid concerns. Nevertheless, the limited evidence that is available suggests that transcriptomic analysis in nutritional intervention studies is feasible and can be highly informative.

The most obvious source of cellular RNA for such studies is blood since this is readily obtained and, as such, ideally suited to gene-expression based biomarker development. However, just as with most solid tissues, blood contains a number of different cell types, each with their own unique gene transcript profile. This must be taken into consideration when performing gene transcript analyses with blood samples. Although red blood cells (erythrocytes) are by far the most abundant

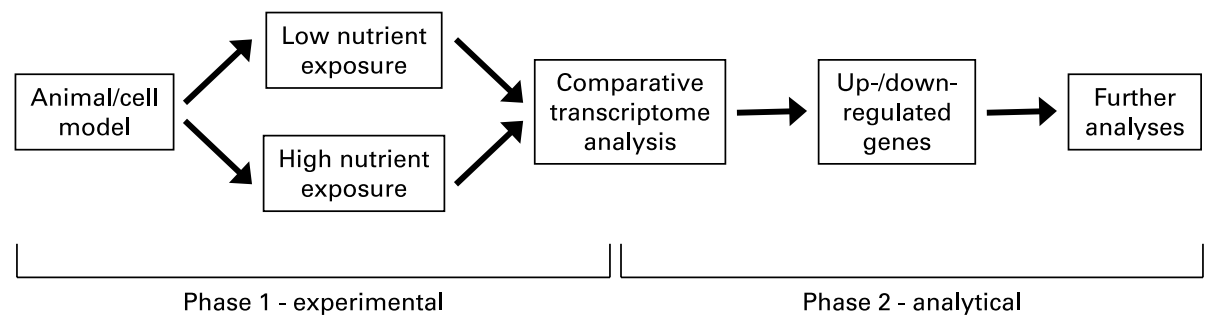

Fig. 2. Schematic representation of the most common experimental format employed for nutritional studies employing transcriptomics analysis. 
Table 1. Examples of published transcriptomic studies examining the effects of iron on gene expression profiles

\begin{tabular}{|c|c|c|c|}
\hline Reference & Experimental system & Experimental conditions & Summary of study Conclusions \\
\hline Jones et al. ${ }^{(33)}$ & Mouse hippcampus & $\begin{array}{l}\text { Variation in hippocampal Fe, } \\
\mathrm{Cu} \text { and } \mathrm{Zn} \text { concentration }\end{array}$ & Expression of 25 genes correlated with levels of at least 1 of the 3 metals \\
\hline Rodriguez et al. ${ }^{(34)}$ & Mouse skeletal muscle and heart & Fe overload & $\begin{array}{l}\text { Expression of } 54 \text { genes and } 75 \text { genes affected by iron overload in skeletal muscle and heart, } \\
\text { respectively including genes included involved in glucose and lipid metabolism, gene } \\
\text { transcription and cellular stress }\end{array}$ \\
\hline Coppin et al. ${ }^{(21)}$ & Mouse liver and duodenum & He knockout & $\begin{array}{l}\text { Expression of } 1,343 \text { and } 370 \text { genes in altered in liver and duodenum, respectively, } \\
\text { of } \mathrm{HfE}-/- \text { mice compared to wild-type. In liver HfE disruption up-regulated genes } \\
\text { involved in antioxidant defence and down-regulated expression of genes involved in } \\
\text { fatty acid } \beta \text {-oxidation, cholesterol catabolism and mitochondrial iron trafficking. } \\
\text { In duodenum Hfe disruption associated with up-regulation of genes involved in iron transpor }\end{array}$ \\
\hline Abgueguen et al. (22) & Mouse duodenal epithelium & Hfe knockout and iron overload & $\begin{array}{l}\text { Expression of } 151 \text { genes altered in } \mathrm{Hfe}(-/-) \text { mice compared with normal littermates, } \\
\text { including genes involved in mucus production and cell maintenance }\end{array}$ \\
\hline Collins et al. ${ }^{(35)}$ & Rat Duodenum & Fe deprivation & $\begin{array}{l}20 \text { genes increased in all ages (e.g. DMT1, DcytB, TfR1, HO-1, ATP7a, MT); } 4 \text { genes } \\
\text { decreased in all ages }\end{array}$ \\
\hline Tamura et al. ${ }^{(36)}$ & Human hepatocytes & Lactoferrin transgene expression & Expression of 9 genes increased and 19 genes decreased \\
\hline Bedrine-Ferran et al. ${ }^{(37)}$ & Caco-2 cell line & Differentiation & $\begin{array}{l}\text { Expression of } 80 \text { genes down-regulated (including HEPH, DMT1, IREG/Fpn and TF) } \\
\text { and } 50 \text { genes up-regulated (including ATP7B and ZIP1) }\end{array}$ \\
\hline Martin et al. ${ }^{(38)}$ & Mouse embryo & Hecpidin transgene expression & Reduced TfR \\
\hline Muckenthaler et al. ${ }^{(39)}$ & Mouse duodenum/liver & Hfe knockout & Altered expression of ZIP1, Cybrd1 and hepcidin \\
\hline Muckenthaler et al. ${ }^{(40)}$ & HeLa cells & Fe donors/chelators & $\begin{array}{l}\text { Expression of } 8 \text { genes induced by loading (HO-1, Hsp70D, Hsp 105, mHsp70, c-myc, } \\
\text { L-Fer, Gas-1 and Gas-3). Expression of } 6 \text { genes induced by iron deficiency (TfR-1, } \\
\text { DMT-1, c-jun, Mt-2, lysyl oxidase, Hif-1) }\end{array}$ \\
\hline Bilello et al. ${ }^{(41)}$ & Rat hepatocytes & Fe overload & Expression of 258 and 627 genes increased and decreased, respectively \\
\hline Alcantara et al. ${ }^{(42)}$ & HL-60 promonocytes & Fe deprivation during differentiation & $\begin{array}{l}\text { Expression of } 11 \text { genes suppressed (Rb, p21, bad, cdk2, cyclins A, D3 and E1, } \\
\text { c-myc, egr-1, iNOS, FasL) }\end{array}$ \\
\hline
\end{tabular}


Table 2. Examples of published transcriptomic studies examining the effects of zinc on gene expression profiles

\begin{tabular}{|c|c|c|c|}
\hline Reference & Experimental system & Experimental conditions & Summary of study Conclusions \\
\hline Jones et al. ${ }^{(33)}$ & Mouse hippcampus & $\begin{array}{l}\text { Variation in hippocampal Fe, } \\
\mathrm{Cu} \text { and } \mathrm{Zn} \text { concentrations }\end{array}$ & Expression of 25 genes correlate with levels of at least 1 of the metals \\
\hline Mazzatti et al. ${ }^{(23)}$ & Human peripheral blood mononuclear cells & Ex vivo $\mathrm{Zn}$ exposure & $\begin{array}{l}\text { Expression of } 68 \text { and } 61 \text { genes affected in cells from young and old donors, respectively. } \\
\text { Pathways affected included tryptophan metabolism, eicosanoid signalling, p38 MAPK } \\
\text { signalling, integrin signalling, purine metabolism, G-protein coupled receptor signalling } \\
\text { and PPAR signalling }\end{array}$ \\
\hline Sun et al. ${ }^{(43)}$ & Rat liver & Zn deficiency and excess & Expression of 62 and genes affected by $Z n$ deficiency and excess, respectively \\
\hline Yamada et al. ${ }^{(4)}$ & HeLa cells & Zn supplementation or deficiency & Expression of 7 genes increased and 4 genes decreased \\
\hline Haase et al. ${ }^{(45)}$ & Human monocyte, $T$ cell and $B$ cell lines & Zn supplementation or deficiency & $\begin{array}{l}\text { Expression of several hundred genes affected by } \mathrm{Zn} \text { including genes related to } \\
\text { pro-inflammatory cytokines and cellular survival. Seven genes (all involved in } \\
\mathrm{Zn} \text { homoeostasis) regulated by zinc in } 3 \text { cell lines }\end{array}$ \\
\hline Tang et al. ${ }^{(46)}$ & $\begin{array}{l}\text { Human mesenchymal stem cells directed } \\
\text { into the osteogenic lineage }\end{array}$ & $\begin{array}{l}\text { Over-expression of ZIP1 } \\
\text { Zn transporter }\end{array}$ & $\begin{array}{l}\text { Expression of } 323 \text { genes affected by over-expression of ZIP1 including cell-matrix adhesion } \\
\text { proteins, metalloproteinases, membrane transporters, signalling molecules, regulators of } \\
\text { transcription/translation, proliferation/differentiation, nucleic and amino acid metabolism, } \\
\text { metal ion homeostasis, apoptosis and motility }\end{array}$ \\
\hline Tom Dieck et al. ${ }^{(47)}$ & Rat liver & Zn deficiency & Expression of 268 gene transcripts altered including 43 involved in lipid metabolism \\
\hline Andree et al. ${ }^{(48)}$ & Human lymphoblastoid cell line & Zn supplementation & Expression of 30 genes affected ( 21 up-regulated and 9 down-regulated) \\
\hline Kindermann et al. ${ }^{(49)}$ & HT-29 cells & Zn depletion & $\begin{array}{l}\text { Expression of } 309 \text { genes altered, including genes involved in intermediary metabolism, } \\
\text { signalling; cell cycle control and growth, vesicular trafficking, cell-cell interaction, } \\
\text { cytoskeleton and transcription control }\end{array}$ \\
\hline Cousins et al. ${ }^{(50)}$ & THP-1 cells & Zn depletion/supplementation & 1,045 genes significantly altered \\
\hline Inoue et al. ${ }^{(51)}$ & Mouse heart & ZNT5 null mice & Expression of 12 genes altered, immediate-early genes \\
\hline Blanchard et al. ${ }^{(52)}$ & Rat small intestine & Zn deficiency & $\begin{array}{l}\text { Ranked lists of up-and down-regulated genes including genes involved in signalling, } \\
\text { growth, transcription, redox and energy utilization }\end{array}$ \\
\hline Moore et al. ${ }^{(53)}$ & Mouse thymus & Zn deficiency & Expression of genes affected \\
\hline
\end{tabular}


cell type in blood, they pose a number of technical problems for gene expression analysis. Firstly, mature erythrocytes are anucleate and, therefore, are unable to modify gene transcription in response to environmental changes. Instead, gene transcript profiles of erythroytes are effectively set in the immature reticulocyte. Secondly, the quantity and quality of RNA in an erythrocyte will depend on its age since no new mRNA can be synthesized after the cell loses its nucleus and RNA present at this stage will inevitably undergo some degradation over time. Finally, haemoglobin mRNA predominates in reticulocytes, reflecting the highly specialised function of red cells. This predominance of a single message can hamper microarray analysis.

For these reasons, white blood cells (leukocytes) are commonly used for gene transcript analysis. Leukocytes have been described as scouts, maintaining continuous surveillance for signs of infection or other threats ${ }^{(15)}$. Equally, they are exposed to acute and chronic fluctuations in plasma composition arising from the sporadic and varied nature of the diet and the metabolic consequences of exposure to different levels and types of dietary components. Thus they represent a potentially valuable and widely used tool for nutritional intervention studies with human subjects both as direct targets for studying effects on immune and inflammatory processes and as surrogates for direct sampling of less accessible tissues.

There are a number of different types of leukocytes (generally categorised into neutrophils, eosinophils, basophils, lymphocytes and monocytes although some of these categories can be further sub-divided). The relative proportions of these different cell types can vary somewhat from sample to sample, with knock-on effects on the 'average' gene expression profiles ${ }^{(16)}$. This noise can be reduced by isolation and analysis of specific leukocyte sub-sets although care should be taken to avoid, or at least minimise, the risk of introducing artefacts in gene expression that could arise from environmental stresses applied to the cells during the additional isolation steps ${ }^{(17)}$.

Analyses of normal variation in leukocyte gene expression suggest that it is best to design studies in which subjects act as their own controls, since the extent of intra-individual variation, in the absence of any intervention, is markedly lower than that of inter-individual variation ${ }^{(15-17)}$. Using such an approach, van Erk and co-workers were able to characterise the specific acute effects of a high-protein and a high-carbohydrate breakfast on the expression of a range of genes in blood leukocytes obtained from human volunteers ${ }^{(18)}$. The response to the high carbohydrate meal was notably associated with changes in expression of genes involved in glycogen metabolism, whereas the response to the high protein breakfast was noted to include altered expression of genes involved in protein biosynthesis.

By employing microarray analysis of RNA obtained from blood lymphocytes of post-menopausal women before and after dietary supplementation with high-dose purified soy isoflavones, Niculescu and co-workers were able to detect altered expression of a large number of genes, including induction of genes associated with cyclic cAMP signalling and cell differentiation and decreased expression of genes associated with cyclin-dependent kinase activity and cell division. They also found that the response to isoflavone supplementation was dependent on the volunteers' capacity to produce equol. This observation is interesting since equol is a bacterial metabolite of the isoflavone daidzein to which some of the beneficial effects of isoflavones have been tentatively attributed. The capacity to metabolise daidzein to equol is dependent the microflora of the gut, such that approximately 30-40\% of humans produce it. Thus the data from this study could provide new insights into functional effects of equol in relation to the apparent beneficial effects of isoflavones ${ }^{(19)}$.

The recent study of Pagmantidis and co-workers, demonstrated that a 6 week dietary supplementation of human volunteers with moderate levels of selenium elicited small but detectable changes in the expression of blood lymphocyte genes, in particular of genes encoding proteins that function in protein biosynthesis ${ }^{(20)}$. Overall, these data clearly support the potential value of transcriptomic analysis of human tissue samples in human nutritional intervention studies.

\section{Analytical methods for transcriptomic studies and the development of new nutritional biomarkers}

As noted above, microarray analysis of samples from nutritionally relevant studies in animal and cell models have led to the identification of many genes that are regulated at the mRNA level by exposure to different dietary components. This information has helped to provide new insights into the range of biological processes that can be affected by different nutritional parameters but a great deal more can and should be done in this regard. Closer inspection of the literature suggests that, in the past, there has been a widespread tendency to allocate insufficient time and resources for the data analysis phase of transcriptomic studies (phase 2 in Fig. 1), with many studies achieving little more than generating lists of up and downregulated genes. This is entirely understandable, since the complexity of the analytical process is often not fully appreciated until it is attempted firsthand. Such vast datasets require time, unique expertise and advanced computing tools to interpret properly. However, the number of people with relevant expertise and the range of analytical tools have increased and become more widely accessible and this, in turn, is reflected in the more detailed analyses performed in the more recent studies. Functional and pathway analysis, literature mining tools, are now employed routinely, providing a clearer biological context for the results obtained and, just as importantly, facilitating cross-study comparisons ${ }^{(21-26)}$. Improvements in data quality and data normalisation strategies together with the development of powerful statistical approaches, such as gene set enrichment analysis, have combined to enhance the sensitivity of transcriptomic methods to such an extent that they genuinely compete with real-time RT-PCR, widely considered as the 'gold standard', in detecting subtle changes in gene expression ${ }^{(26,27)}$. This is particularly important for nutrition research where only small changes in gene expression are generally expected to be brought about by dietary modification but, nevertheless, such changes may have profound effects in the long term on health.

In terms of gene expression-based biomarker development, progress to date has been more disappointing. In a few cases, results from nutritionally-relevant transcriptomic studies performed in vitro or in animal models have been taken forward into human studies to the test the effects of nutritional interventions on the mRNA levels of individual genes in circulating blood leukocytes using techniques such as real time 
RT-PCR ${ }^{(28)}$. Such studies provide further evidence that nutrient regulated changes in the expression of specific genes can be detected in vivo in samples from human subjects. But, although a number of potential gene expression-based nutrient sensitive biomarkers have been identified, these suffer from potential confounding effects that undermine their value. This reflects a fundamental problem with the specificity of single genes as biomarkers since expression of most (perhaps all) individual genes can be regulated by more than one environmental factor.

An interesting alternative that may help to overcome this problem is the development of markers based on expression profile 'signatures' rather than single genes. Such 'signatures' (characteristic patterns of differential gene expression) are effectively measures of cell phenotype, and can be used to look for novel biomarkers in cells that have been exposed to different levels of micronutrients. Approaches designed to identify characteristics gene expression 'signatures' are being developed and tested widely in the context of medical research, in particular cancer research $^{(29-32)}$. Although still in a comparatively early developmental stage, the applicability and power of such approaches should also be evaluated in the context of nutrition.

\section{Conclusions}

Even during their initial developmental phase, transcriptomic approaches have already provided many valuable new insights into diet-gene interactions. Now the technology has reached a sufficient level of maturity that it can be used as a routine tool by all researchers who wish to exploit it to produce high quality data. The emphasis needs to shift towards more extensive, disciplined and detailed examination of the data generated by using advanced statistical, data- and literature-mining tools. The development of universal standards and infrastructures for microarray data capture, storage and sharing will be vital in ensuring that data produced can used to it full potential. Although not yet comprehensively tested, the scope for human nutritional intervention studies, which employ transcriptomic analysis of accessible tissues, appears very promising. This kind of study represents an exciting avenue of investigation for the development of new nutritional biomarkers.

\section{Acknowledgements}

The Institute of Food Research is funded by the Biotechnology \& Biological Sciences Research Council (BBSRC), UK. Dr Elliott is a member of NuGO The European Nutrigenomics Organisation: linking genomics, nutrition and health research (NuGO, CT-2004-505944) a Network of Excellence funded by the European Commission's Research Directorate General under Priority Thematic Area 5 Food Quality and Safety Priority of the Sixth Framework Programme for Research and Technological Development. The content of this article presents no conflicts of interests.

\section{References}

1. Elliott R \& Ong TJ (2002) Nutritional genomics. BMJ 324, $1438-1442$.

2. Corthesy-Theulaz I, den Dunnen JT, Ferre P, Geurts JM, Muller M, van Belzen N \& van Ommen B (2005) Nutrigenomics: the impact of biomics technology on nutrition research. Ann Nutr Metab 49, 355-365.

3. Kaput J (2007) Developing the promise of nutrigenomics through complete science and international collaborations. Forum Nutr 60, 209-223.

4. van Ommen B \& Stierum R (2002) Nutrigenomics: exploiting systems biology in the nutrition and health arena. Curr Opin Biotechnol 13, 517-521.

5. Kussmann M, Raymond F \& Affolter M (2006) Omics-driven biomarker discovery in nutrition and health. J Biotechnol 124, $758-787$.

6. Schena M, Shalon D, Davis RW \& Brown PO (1995) Quantitative monitoring of gene expression patterns with a complementary DNA microarray. Science 270, 467-470.

7. Guo L, Lobenhofer EK, Wang C, et al. (2006) Rat toxicogenomic study reveals analytical consistency across microarray platforms. Nat Biotechnol 24, 1162-1169.

8. Xing Y, Kapur K \& Wong WH (2006) Probe selection and expression index computation of affymetrix exon arrays. PLoS ONE 1, e88.

9. Gardina PJ, Clark TA, Shimada B, et al. (2006) Alternative splicing and differential gene expression in colon cancer detected by a whole genome exon array. BMC Genomics 7, 325 .

10. Brazma A, Hingamp P, Quackenbush J, et al. (2001) Minimum information about a microarray experiment (miame)-toward standards for microarray data. Nat Genet 29, 365-371.

11. Spellman PT, Miller M, Stewart J, et al. (2002) Design and implementation of microarray gene expression markup language (mage-ml). Genome Biol 3, RESEARCH0046.

12. Parkinson H, Sarkans U, Shojatalab M, et al. (2005) Arrayexpress-a public repository for microarray gene expression data at the ebi. Nucleic Acids Res 33, D553-D555.

13. Barrett T, Suzek TO, Troup DB, et al. (2005) Ncbi geo: mining millions of expression profiles-database and tools. Nucleic Acids Res 33, D562-D566.

14. Rocca-Serra P \& Elliott RM (2006) Data storage: bringing us a step closer to data sharing? Br J Nutr 95, 1237-1239.

15. Whitney AR, Diehn M, Popper SJ, Alizadeh AA, Boldrick JC, Relman DA \& Brown PO (2003) Individuality and variation in gene expression patterns in human blood. Proc Natl Acad Sci U S A 100, 1896-1901.

16. Radich JP, Mao M, Stepaniants S, et al. (2004) Individualspecific variation of gene expression in peripheral blood leukocytes. Genomics 83, 980-988.

17. Eady JJ, Wortley GM, Wormstone YM, Hughes JC, Astley SB, Foxall RJ, Doleman JF \& Elliott RM (2005) Variation in gene expression profiles of peripheral blood mononuclear cells from healthy volunteers. Physiol Genomics 22, 402-411.

18. van Erk MJ, Blom WA, van Ommen B \& Hendriks HF (2006) High-protein and high-carbohydrate breakfasts differentially change the transcriptome of human blood cells. Am J Clin Nutr 84, 1233-1241.

19. Niculescu MD, Pop EA, Fischer LM \& Zeisel SH (2007) Dietary isoflavones differentially induce gene expression changes in lymphocytes from postmenopausal women who form equol as compared with those who do not. J Nutr Biochem 18, 380-390.

20. Pagmantidis V, Meplan C, van Schothorst EM, Keijer J \& Hesketh JE (2008) Supplementation of healthy volunteers with nutritionally relevant amounts of selenium increases the expression of lymphocyte protein biosynthesis genes. Am J Clin Nutr 87, 181-189.

21. Coppin H, Darnaud V, Kautz L, Meynard D, Aubry M, Mosser J, Martinez M \& Roth MP (2007) Gene expression profiling of hfe $-/-$ liver and duodenum in mouse strains with differing susceptibilities to iron loading: identification of transcriptional regulatory targets of hfe and potential hemochromatosis modifiers. Genome Biol 8, R221. 
22. Abgueguen E, Toutain B, Bedrine H, et al. (2006) Differential expression of genes related to hfe and iron status in mouse duodenal epithelium. Mamm Genome 17, 430-450.

23. Mazzatti DJ, Malavolta M, White AJ, Costarelli L, Giacconi R, Muti E, Cipriano C, Powell JR \& Mocchegiani E (2007) Differential effects of in vitro zinc treatment on gene expression in peripheral blood mononuclear cells derived from young and elderly individuals. Rejuvenation Res 10, 603-620.

24. Scherf M, Epple A \& Werner T (2005) The next generation of literature analysis: integration of genomic analysis into text mining. Brief Bioinform 6, 287-297.

25. Gentleman RC, Carey VJ, Bates DM, et al. (2004) Bioconductor: open software development for computational biology and bioinformatics. Genome Biol 5, R80.

26. Mootha VK, Lindgren CM, Eriksson KF, et al. (2003) Pgc-1alpharesponsive genes involved in oxidative phosphorylation are coordinately downregulated in human diabetes. Nat Genet 34, 267-273.

27. Subramanian A, Tamayo P, Mootha VK, et al. (2005) Gene set enrichment analysis: a knowledge-based approach for interpreting genome-wide expression profiles. Proc Natl Acad Sci U S A 102, $15545-15550$

28. Aydemir TB, Blanchard RK \& Cousins RJ (2006) Zinc supplementation of young men alters metallothionein, zinc transporter, and cytokine gene expression in leukocyte populations. Proc Natl Acad Sci U S A 103, 1699-1704.

29. Naderi A, Teschendorff AE, Barbosa-Morais NL, et al. (2007) A gene-expression signature to predict survival in breast cancer across independent data sets. Oncogene 26, 1507-1516.

30. Lyman GH \& Kuderer NM (2006) Gene expression profile assays as predictors of recurrence-free survival in early-stage breast cancer: a metaanalysis. Clin Breast Cancer 7, 372-379.

31. Marchionni L, Wilson RF, Wolff AC, Marinopoulos S, Parmigiani G, Bass EB \& Goodman SN (2008) Systematic review: gene expression profiling assays in early-stage breast cancer. Ann Intern Med 148, 358-369.

32. Xu L, Tan AC, Winslow RL \& Geman D (2008) Merging microarray data from separate breast cancer studies provides a robust prognostic test. BMC Bioinformatics 9, 125.

33. Jones LC, Beard JL \& Jones BC (2008) Genetic analysis reveals polygenic influences on iron, copper, and zinc in mouse hippocampus with neurobiological implications. Hippocampus $\mathbf{1 8}$ 398-410.

34. Rodriguez A, Hilvo M, Kytomaki L, Fleming RE, Britton RS, Bacon BR \& Parkkila S (2007) Effects of iron loading on muscle: genome-wide mrna expression profiling in the mouse. BMC Genomics 8, 379.

35. Collins JF, Franck CA, Kowdley KV \& Ghishan FK (2005) Identification of differentially expressed genes in response to dietary iron deprivation in rat duodenum. Am J Physiol Gastrointest Liver Physiol 288, G964-G971.

36. Tamura T, Nozaki A, Abe K, Dansako H, Naka K, Ikeda M, Tanaka K \& Kato N (2005) Cdna microarray analysis of lactoferrin expression in non-neoplastic human hepatocyte $\mathrm{ph} 5 \mathrm{ch} 8$ cells. Biochim Biophys Acta 1721, 73-80.

37. Bedrine-Ferran H, Le Meur N, Gicquel I, et al. (2004) Transcriptome variations in human caco- 2 cells: a model for enterocyte differentiation and its link to iron absorption. Genomics 83, 772-789.

38. Martin ME, Nicolas G, Hetet G, Vaulont S, Grandchamp B \& Beaumont C (2004) Transferrin receptor 1 mRNA is downregulated in placenta of hepcidin transgenic embryos. FEBS Lett 574, 187-191.

39. Muckenthaler M, Roy CN, Custodio AO, Minana B, deGraaf J, Montross LK, Andrews NC \& Hentze MW (2003) Regulatory defects in liver and intestine implicate abnormal hepcidin and cybrd1 expression in mouse hemochromatosis. Nat Genet 34, $102-107$.

40. Muckenthaler M, Richter A, Gunkel N, et al. (2003) Relationships and distinctions in iron-regulatory networks responding to interrelated signals. Blood 101, 3690-3698.

41. Bilello JP, Cable EE \& Isom HC (2003) Expression of e-cadherin and other paracellular junction genes is decreased in iron-loaded hepatocytes. Am J Pathol 162, 1323-1338.

42. Alcantara O, Kalidas M, Baltathakis I \& Boldt DH (2001) Expression of multiple genes regulating cell cycle and apoptosis in differentiating hematopoietic cells is dependent on iron. Exp Hematol 29, 1060-1069.

43. Sun JY, Wang JF, Zi NT, Jing MY \& Weng XY (2007) Gene expression profiles analysis of the growing rat liver in response to different zinc status by cdna microarray analysis. Biol Trace Elem Res 115, 169-185.

44. Yamada H, Suzuki K \& Koizumi S (2007) Gene expression profile in human cells exposed to zinc. J Toxicol Sci 32, 193-196.

45. Haase H, Mazzatti DJ, White A, Ibs KH, Engelhardt G, Hebel S, Powell JR \& Rink L (2007) Differential gene expression after zinc supplementation and deprivation in human leukocyte subsets. Mol Med 13, 362-370.

46. Tang Z, Sahu SN, Khadeer MA, Bai G, Franklin RB \& Gupta A (2006) Overexpression of the zip1 zinc transporter induces an osteogenic phenotype in mesenchymal stem cells. Bone $\mathbf{3 8}$ 181-198.

47. Tom Dieck H, Doring F, Fuchs D, Roth HP \& Daniel H (2005) Transcriptome and proteome analysis identifies the pathways that increase hepatic lipid accumulation in zinc-deficient rats. J Nutr 135, 199-205.

48. Andree KB, Kim J, Kirschke CP, Gregg JP, Paik H, Joung H, Woodhouse L, King JC \& Huang L (2004) Investigation of lymphocyte gene expression for use as biomarkers for zinc status in humans. J Nutr 134, 1716-1723.

49. Kindermann B, Doring F, Pfaffl M \& Daniel H (2004) Identification of genes responsive to intracellular zinc depletion in the human colon adenocarcinoma cell line ht-29. J Nutr 134, $57-62$.

50. Cousins RJ, Blanchard RK, Popp MP, Liu L, Cao J, Moore JB \& Green CL (2003) A global view of the selectivity of zinc deprivation and excess on genes expressed in human thp-1 mononuclear cells. Proc Natl Acad Sci U S A 100, 6952-6957.

51. Inoue K, Matsuda K, Itoh M, et al. (2002) Osteopenia and malespecific sudden cardiac death in mice lacking a zinc transporter gene, znt5. Hum Mol Genet 11, 1775-1784.

52. Blanchard RK, Moore JB, Green CL \& Cousins RJ (2001) Modulation of intestinal gene expression by dietary zinc status: effectiveness of cdna arrays for expression profiling of a single nutrient deficiency. Proc Natl Acad Sci U S A 98, 13507-13513.

53. Moore JB, Blanchard RK, McCormack WT \& Cousins RJ (2001) Cdna array analysis identifies thymic lck as upregulated in moderate murine zinc deficiency before t-lymphocyte population changes. $J$ Nutr 131, 3189-3196. 